\title{
An approach for the evaluation and implementation of mixed rail operations in harmony with non-motorized trails and urban structure: the case of Xalapa, Mexico
}

\author{
D. Camacho \& U. Martin \\ Railway and Transportation Engineering Institute, \\ University of Stuttgart, Germany
}

\begin{abstract}
An integrated transportation system is a prerequisite for urban sustainability. Inefficient transportation systems contribute to pollution, increase transportation time and costs, and promote urban sprawl. Midsize Mexican cities are increasingly vulnerable to these problems due to planning that focuses on individual mobility and separation of land uses. Part of the solution presented in this paper through the case of the city of Xalapa, Mexico is to use existing underutilized urban railroad corridors for the implementation of light and freight rail mixed operations with non-motorized trails. The solution promotes multimodal mobility, accessibility, and connectivity while making use of resources efficiently through multifunctional spaces and infill development. These in turn increase train operation safety and capacity, reduce urban barriers, promote harmonious citytrain coexistence and urban compactness. Mixed rail operation with trails is complex and their technical, technological, operational, and institutional aspects need to be established and adapted from existing models. This paper is the first step toward establishing the requirements for implementation in the context of midsize Mexican cities. The findings would be the basis for the development of a standardized evaluation framework to determine the system's feasibility. The framework is based on a German evaluation scheme used for the evaluation of large public transportation investments.

Keywords: underutilized track, mixed rail operations, shared track, light rail, freight rail, rails-with-trails, non-motorized transport, standardized evaluation.
\end{abstract}




\section{Introduction and objectives}

Cities today face an ever increasing need to procure land and financial means to provide the mobility and accessibility required for a functional and sustainable city. The norm in many Mexican cities is a lack of high quality, integrated transportation systems, which results in low standards of living partly due to longer commuting distances and times, road congestion, and pollution. An available solution to provide a mass, well-coordinated and demand oriented transportation system that helps mitigate these issues is the use of underutilized railway corridors for mixed rail operations that include trails along the track for non-motorized transportation (NMT). Many underutilized or abandoned railroad corridors often traverse densely populated areas and connect important and even strategic destinations; hence representing an attractive option for the provision of flexible, high quality transit services right where people live that connect them to places they want to go. Mixed rail operations promote an efficient use of resources by maximizing the use of existing infrastructure and land while preventing environmental and social problems related to transportation projects.

This paper continues a study which explored the sensibility and possibility of implementing a mixed rail operation or shared track with trail system on an underutilized railroad corridor in the city of Xalapa, Mexico (Camacho [1]). The corridor was analyzed in regards to the urban structure around it, available space, demographic aspects, and characteristics that would support a light rail transit (LRT) system and justify a trail. The study concluded that the corridor is suitable for the implementation of a shared track with trail system, but that further studies should establish additional requirements and its economic feasibility. The goal of this study is to create a framework that identifies and describes the additional requirements in terms of preconditions for implementation and formalizes the characteristics that determine the suitability of railway corridors. In addition, it establishes the institutional, technical, and operational aspects to be considered, analyzed and evaluated. The evaluation will be derived and adapted to Mexico from a standardized scheme used in Germany for determining the feasibility of large-scale public transportation systems. Technical norms, technology, and regulations for track sharing and trails do not exist in Mexico. One aim of this paper is to attract the attention of authorities to start the process of their creation.

\section{Mixed rail operation and rails-with-trails}

Mixed rail operation or shared track is the "commingled, simultaneous train operation on shared track by railroad trains (e.g. freight) and rail transit vehicles". In the US, it is implemented under strict temporal separation (e.g. transit services during day time and freight at night), but commingled and simultaneous operation is possible after providing a "high burden of proof" regarding safety; however, this has not been attempted in the US (Phraner et al. [2]). A variant from Europe, is the "tram-train" defined as "a railroad system that produces a direct connection between the regional area of a city and its town center. In the city it runs on tram tracks and follows tram regulations. In the region, it runs on railroad tracks and 
follows heavy rail regulations with additional requirements" (Naegeli et al. [3]). The NMT trail along the tracks, known as rails-with-trails is "a multi-use trail along railroad lines that are still active" (Birk et al. [4]).

The system proposed in this study is defined as a commingled shared track with a trail within an urban center, which does not provide a regional service. However, the system is conceived with the idea of expanding it as a regional tram-train if the right conditions arise (e.g. regional travel demand to the city).

\subsection{Expected benefits of the proposed concept}

There are several benefits associated with shared tracks with trails. The most obvious is the use of existing infrastructure in a multifunctional and cost effective manner; increasing land and track productivity through the provision of a high quality transportation system where people live and to places they want go with minimum of transfer penalty (i.e. disconnect between two segments of a transit trip). Likewise, LRT systems spark urban development (Phraner et al. [5]); hence municipal revenue is potentially increased when paired with value capture strategies. Additionally, as mentioned by Birk et al. [4], rail-with-trail (RWT) projects reduce trespassing, dumping, and vandalism, particularly in areas with a history of such problems, thus increasing safety and track capacity. A trail also encourages non-motorized and public transportation (PuT) integration; while increasing transportation choices and transit ridership, this benefit is enhanced if the LRT is paired with a well-coordinated bus feeder system. An important aspect of a trail is its potential to minimize urban barriers; achieved through a linear park that becomes a destination rather than a monofunctional transportation corridor. Also, through the care of the space by local authorities and park-like characteristic of the trail, issues like garbage and poor drainage will be mitigated. This should also be attractive to the concessionaire, since improving drainage prevents track degradation, which results in lower maintenance costs.

\subsection{Main challenge: safety}

There are many complex challenges regarding shared track and RWT that need to be recognized and dealt with accordingly. Most relate to safety and liability:

\subsubsection{Mixed rail operation/shared track}

US transportation agencies regard mixed light and freight rail as incompatible in regards to safety, which leads to liability issues. The biggest concern is the use of non-compliant rolling stock on railroads. Hence, US policy concentrates on collision protection resulting in absolute temporal separation of involved trains. Commingled use of tracks is possible, but is not favored (Phraner et al. [2]). Temporal separation might constitute an unattractive option to operators, since frequency and flexibility of operations is constrained; additionally, revenue and operation expansion is restricted. The German philosophy and experience offer excellent examples of capacity and safety. In Germany safety is also a concern, but the philosophy is collision avoidance and impact attenuation (Phraner et al. [2]). A safe operation involves better signal and control systems, a central, rigid 
and disciplined operating program and dispatching practices that maintain an excellent safety record as displayed by the Karlsruhe Model (Figure 1); the most advanced system which shows system incremental expansion using surplus track capacity in a financially feasible manner (Phraner et al. [2]).

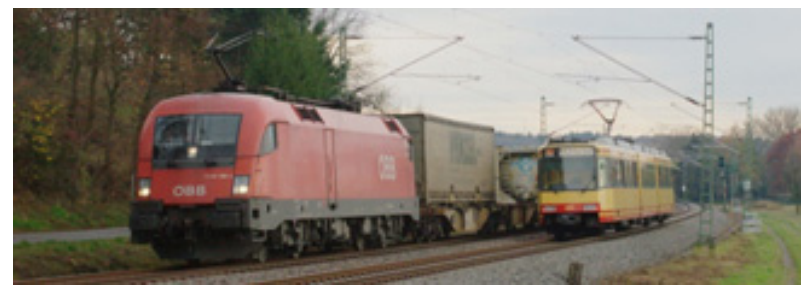

Figure 1: Track sharing and trail in Karlsruhe, Germany. (Source: Benjamin Kehrer.)

\subsubsection{Rails-with-trails}

In the US bringing people close to live tracks seems in direct opposition to what railroad operators perceive as a good safety and operational practice. Railroad owners worry about vandalism, trespassing, injuries and fatalities; they are in the business of trains and anything not related to trains would be of minimum priority and need to perceive a benefit before accepting any intervention in their right-ofway (Birk et al. [4]). In Europe, however (Figure 2), paths are common along shared tracks (Phraner et al. [5]).

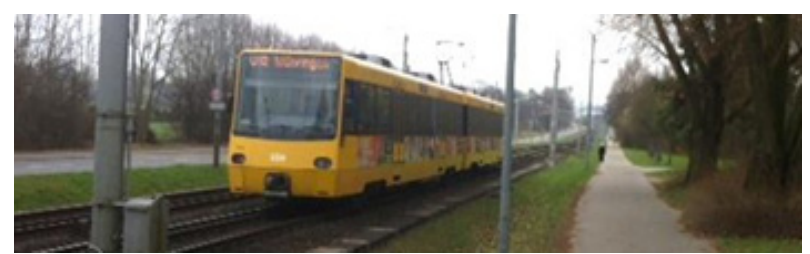

Figure 2: Trails along German tram lines are common (e.g. Stuttgart).

Finding a common ground and benefits for the railroad can spark the support needed for implementation (Birk et al. [4]).

\section{The Mexican context and the study area}

\subsection{Mexican railroads}

Mexico has an extensive railroad infrastructure, which was privatized in 1995 . The privatization consists of granting 50-year concessions for the exploitation of railroad lines (Congreso [6]). Privatization sought to increase productivity and competiveness. The role of the government, owner of the infrastructure, is to set policies for further development. Although the main focus has been freight transport, passenger services still can be implemented on any track, at any point 
in time and through any interested agent so long the project includes the technical and operational aspects that ensure safety, feasibility studies, and financing schemes (Congreso [6]). Regulations strongly protect the rights to track access, which need to be negotiated with operators in terms of charges, types of service allowed, permissible volumes of traffic, dispatching priority, etc. The government will only establish its classification, characteristics and modalities of operation (Congreso [6]). Railroads and train based public transit (i.e. LRT) are regulated under the same governmental agency, although transit is operated by local governments. The few passenger and transit systems that exist occur mainly on exclusive right-of-ways, so there are no mixed traffic systems. Passenger systems on existing tracks are implemented on corridors with extra capacity (only one, under time separation) or abandoned tracks (Gorostiza [7]), which in cities, often cross densely populated areas (Camacho [1]). Examples of transit systems in Mexico provide no sign as to whether a commingled mixed rail operation would be rejected or accepted. However, the lack of shared track regulations and norms represents both a concern and an opportunity.

\subsection{Xalapa}

Xalapa is the capital of the state of Veracruz; it has a population of about 470,000 inhabitants and a population of 600,000 in its greater area. The municipality of Xalapa is urban in character and still displays a compact structure despite its master plan, which encourages sprawl and separation of uses (Camacho [1]). Xalapa is located between Mexico City and the port of Veracruz, the largest port in Mexico. This places Xalapa in a strategic position, but also creates problems caused by the railroad line that connects the port to Mexico City and the US. Train traffic is expected to grow due to the planed port expansion, which would exacerbate the existing train-city interaction issues (e.g. safety, urban barrier). In Xalapa $40 \%$ of the population uses cars, $40 \%$ uses PuT, and $20 \%$ walks (IDB [8]). Xalapa has no bicycle culture, but efforts are made to introduce the use of bicycles. In Xalapa, there are over 89 bus routes, and 1,208 registered buses that currently offer $50 \%$ more than the needed capacity (IDB [8]). The amount of private cars, taxis and buses surpass the existing available street surface (Camacho [1]), which causes severe congestion problems. This situation creates political and public support for an LRT system on the existing tracks.

\subsection{Xalapa's corridor}

The railroad corridor traversing Xalapa from north to south is approx. $9 \mathrm{~km}$. The track passes through important trip origins and destinations (e.g. housing areas, a long distance bus station, the University) and influences about 122,000 people (IDB [8]). Several large avenues with bus lines cross the corridor. The corridor is under concession to a US freight company (Kansas City Southern de Mexico) and consists of a single track laid on a $1.97 \%$ slope, two former secondary passenger high level platform stations, a main high level platform station and a 20-hectare shunting yard in the middle of the corridor. People live right up to or within the right-of-way, hence trespassing is a frequent issue, causing accidents and forcing the train to operate at low speeds. The line displays a low traffic volume of about 
five trains per day (fewer were observed). Due to the low traffic, gentle slope and connections, people get encouraged to walk on the tracks causing serious safety issues. Social and leisure activities occur in close proximity to the tracks (Camacho [1]). In this sense, the urban barrier caused by the track is mitigated by the people, who at the same time provide clues as to what is required to mitigate issues. Environmental problems are also present due to the lack of maintenance of the right-of-way (e.g. drainage and garbage) and handful of encroachments with no services. One important social issue is crime which is also common due to a lack of municipal security services in the area.

\section{Aspects required for shared track with trail systems}

To be able to create a framework to implement and evaluate the concept, it is necessary to define its preconditions, characteristics, and requirements. The preconditions established in this study are mainly related to political and regulatory aspects; beyond the power of even the best technical solution. In addition, not all urban underutilized tracks would be apt for a shared track system, so the characteristics determining suitability should be established in order to eliminate unsuitable candidates. Aspects that can be solved within reasonable institutional, technical and operational solutions will be listed as requirements. Safety, although part of these aspects, is mentioned on its own since it introduces the concept of liability and risk assessment.

\subsection{Preconditions}

The following is an initial list of preconditions that need to be met before a shared track system is considered:

1. Regulations and technical standards need to exist.

2. Competent authorities need to understand the concept and support it.

3. A champion within the municipal government is needed.

4. Need to improve mobility due to road congestion and deficient PuT.

5. There needs to be a high or relative high PuT culture (Van der Bijl and Kühn [9]).

Some of these aspects are without a doubt complex and appear to be insurmountable, but existing examples show they can be overcome. Additionally, as some of these preconditions are met, they are removed from the list and become the system's regulatory base (e.g. national technical norms).

Other preconditions from the European experience include: recognition of transit needs by federal authorities, transit funding programs, federal funded research (i.e. shared track), regionalization of transit services and privatization of the railroad system, which open for bid any track with operational deficit.

Fortunately, in Mexico many of these preconditions already take place. For instance the federal government does recognize the need for transit systems and has created a program (PROTRAM) which promotes and co-finances transit systems in cooperation with local authorities. Furthermore, a new railroad agency is being created, which will be responsible of conducting research and create 
technical standards and regulations. Lastly, the railroad system in Mexico is privatized and seeks to encourage track productivity through competition and track access rights. Although these issues do not directly address shared track systems, they pave the road for discussion.

\subsection{Characteristics for a suitable corridor}

Several publications list characteristics or check lists for successful track sharing systems. However, they do not completely apply to the system proposed in this paper since their focus is on regional tram-trains or because they reflect another context (e.g. political). The system proposed in this paper reflects the need for a shared track within an urban context. In this sense, the corridor should support the implementation of a transit system. It has already been mentioned that a study performed an evaluation of Xalapa's corridor based on the following characteristics: location of the track around a transport supportive urban structure (i.e. density, land use, land use intensity, origin and destinations, destinations with special functions), low level of freight traffic: hence capacity, and enough width of right-of-way for the implementation of the NMT trail (Camacho [1]).

\subsection{Requirements for a shared track system}

\subsubsection{Institutional aspects}

Track sharing makes use of two different track environments and an organization that understands both systems should be in place to coordinate the operation, including training other personnel regarding operating rules and control systems of both types of operation (Naegeli et al. [3]). For example, a concept that helped advance track sharing in Germany is the implementation of strong oversight local organizations that offer customers a uniform transport system: one network, one schedule, one tariff, one ticket independent of transport undertaking (Phraner et al. [5]). A similar approach to integration and oversight should be implemented in Mexico. Other important aspects often forgotten include the following:

4.3.1.1 Stakeholder collaboration and public participation Coordination and negotiation are essential for shared track and trail systems. Not performing these efficiently would make a project fail. Identifying the important stakeholders and involving them at the right time is crucial. The most common stakeholders are the rail transit authority, freight railroad owner and concessionaire, transit riders, and transportation regulators (Phraner et al. [2]). All these stakeholders have different needs and goals that need to be properly addressed. An often forgotten group is the general public, whose participation implies benefits such as the improvement of the quality of decisions, the increase of ease of implementation, the minimization of costs and delays, the avoidance of worst-case scenario confrontations, the creation of an atmosphere that maintains credibility and legitimacy, the anticipation of public concerns, the opportunity to educate about the new system, and the development of the civil society (Creighton [10]). 
Important is to develop programs that allow stakeholders to voice their opinion in an organized, efficient and respectful manner.

\subsubsection{Urban development and land use-transportation integration One} aim of shared track with trail systems in urban corridors is to improve urban and environmental degradation. In Xalapa, people live and perform their activities in close proximity to the tracks. This creates problems (e.g. safety, littering), which are enhanced by the lack of jurisdiction of the municipal authorities to care for the space. The implementation of a shared track with trail system could improve the issues by involving the stakeholders and forcing them to coordinate and distribute responsibilities in relation to the management of the space. Moreover, the implementation would spark development and urban regeneration, especially if urban and land use planning strategies are in place. In Xalapa, the corridor runs though consolidated urban areas that already display the urban characteristics (e.g. density) that support transit systems (Camacho [1]). The LRT system in turn would enhance the space and formalize it (e.g. it would provide the legal elements that allow transportation and development). In addition, a trail would improve the environmental quality of the space by creating a linear park that acts like an urban seam rather than a barrier, which would also encourage growth. Thus a synergy between urban and transport systems is created. This may sound dangerous in close proximity to a live railroad, but the reality is that the space already experiences great safety problems. Organizing it by placing a linear park type trail and a transit system would discourage people from entering the tracks. As previously mentioned, there is a high correlation between RWT projects and reduced trespassing and vandalism, particularly in areas with a history of such problems. This is because people chose to walk on the trail, and because RWTs channelize users to safe crossings (Birk et al. [4]). What needs to be avoided is the complete confinement of the track with fences or the use of pedestrian bridges instead of crossings; this would exacerbate the urban barrier, and lower accessibility (e.g. people in wheelchairs) and connectivity.

\subsubsection{Technical aspects}

It is important to look into cost effective technical and technological solutions that are safe, flexible, and adaptable. In Mexico, the railroad system is developing and lacks many technical standards; there is room for innovation and adaptation. However, caution needs to be exercised since the rolling stock is similar to that in the US, whose dimensions have conflicts with several aspects of the infrastructure (e.g. overhead wires).

4.3.2.1 Physical plant/infrastructure Operating two different types of train systems has impacts on the infrastructure. The following are infrastructural aspects that may be impacted:

Track bedding: should conform to freight traffic standards due to heavier loads. Cant and alignment: should minimize negative impacts of mixed rail operations and ensure an efficient use of the track. 
Radius: should assure fast, safe and comfortable movement of trains around curves and turnouts without causing an excessive degradation of the track.

Gauge and rail profile: Mexico's railroad system uses standard gauge; however, if a wide profile is chosen, it may promote pedestrian tripping in mixed traffic areas (Phraner et al. [2]). Nonetheless, this allows LRVs to be used in more sections of the railroad network; allowing the expansion of the system if required. Clearance (Dynamic envelope): impacts LRT structures along the track (e.g. platforms), and components like overhead wires since the vertical clearance of US freight rolling stock is larger than the minimum clearance required by LRT catenary systems; thus impacting the vehicle choice.

Stations: station design needs to consider clearance requirements in terms of platforms (high or low), the type of vehicles used, accessibility, information systems and the operational quality (e.g. dwell time).

Civil works: drainage, grading, and other aspects like bridges and tunnels need to be carefully analyzed in regards to capacity, safety and costs.

Operation and maintenance facilities and depot: these facilities can potentially be shared with existing railroad facilities.

Trails: trails along a live railroad line within an urban area need to be carefully designed since it would be used by users with different goals and needs. For the railroad company, however, the barrier design to keep people off the racks is more important, but should not decrease accessibility and connectivity.

4.3.2.2 Vehicles and power systems The biggest limitation for track sharing in the US is the non-compliance of vehicles in terms of buff strength (i.e. crashworthiness). However, increasing the strength is not a viable solution due to the minimum braking performance required; as strength is increased so is the weight and the breaking distance, which has been reported to be the main culprit of up to $80 \%$ of train collisions in Germany (Phraner et al. [2]). The German approach consists of improving signalling and braking systems as well as vehicle design standards that absorb the energy of a crash (Phraner et al. [2]).

In track sharing systems choosing the right vehicle is important since it represents up to $20 \%$ of the total capital cost (ScanRail [11]). The vehicle criteria should include power supply, platforms, operation requirements, functional design for operation optimization, passenger information systems, accessibility, ticket selling and validation, and aesthetics (ScanRail [11]).

Maintaining the system's flexibility and adaptability in terms of rolling stock is also important. As the city of Kassel, Germany shows (Figure 3), it is feasible to operate all-electric and diesel trams and use them as required (Phraner et al.

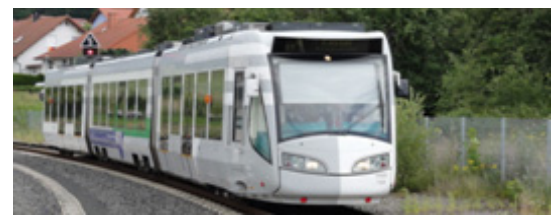

Figure 3: Tram-train in Kassel, Germany: dual mode diesel/electric. (Source: Eastpath.) 
[2]). Flexibility is then increased by the use of wireless vehicles such as DMUs (Diesel Multiple Units) or dual systems (diesel/electric, electric/electric). In addition using vehicles that do not require wayside power supply also represents capital cost savings, which suits the Mexican context. In Mexico track electrification is not common and should be avoided for corridors with freight traffic since the structural gauge of freight trains exceeds the minimum height required for overhead wires.

\subsubsection{Operational aspects}

Safety is the single biggest concern in shared track with trail operations. In track sharing the issue is the non-compatibility of vehicles in terms of crashworthiness. In rails-with-trails the problem is people's proximity to live tracks. Both of these situations increase operators' liability and risks to the users. However, safety in shared track systems can be greatly enhanced through operational aspects that consider and analyze the special characteristics of both train systems. The analysis results in recommendations regarding operational requirements, such as signal and control systems (e.g. systems that allow train to be stopped automatically), communication centers (e.g. can communicate with all trains or set signals), operating rules (speed, length of train, etc.) and programs (train mixture), as well as potential policies, and institutional structure enhancements to ensure the safety of all users (Phraner et al. [2]). Other considerations include train dispatching practices and personnel training in transit and railroad rules and regulations (Phraner et al. [2]).

Safety is also important regarding the different transport systems interacting at crossing and to trail users along the track. For this, it is important to analyze the overall safety of the system in terms of the overlap principle, which calls for comprehensive, beyond the strictly necessary minimum safety measures on the part of all involved modes of transportation. This prevents gaps between transport modes' safety measures that would increase the probability of accidents. Measures at crossings can be technical (e.g. physical barriers) or nontechnical (e.g. signs); including educational. In regards to people along the tracks, it is necessary to establish the geometric and barrier design that would deter trespassing, prevent negative effects on the operation, and keep people at a prudent distance. The measures should encourage users to use crossing points.

However, operational aspects are not limited to safety, they also involve track capacity, which is the maximum number of trains that may be operated on a given infrastructure at the same time while holding an acceptable quality of operation (i.e. waiting time) $[12,13]$. To determine the maximum capacity of a given track, capacity research methods are employed (Martin [14]). The result of the analysis shows the optimal range of track utilization (higher productivity) in terms of a range of trains per unit time which correspond to a desired waiting time value. As such, capacity research can be used to determine the adequate track infrastructure, the appropriate signal and control systems, and to establish the operating performance (Martin [14]). For an urban shared track system, the capacity research analysis should have special considerations in regards to mixed traffic, since the railroad crosses many car and NMT intersections (Martin [15]). 
Capacity research constitutes an important aspect for the track sharing negotiation process since in order to enlist a freight operator, the benefits of new rules and systems need to be quantified. Lastly, it is important that costs involved in upgrading the system are not borne by the concessionaire.

\subsubsection{Safety}

Safety is central to all aspects mentioned. The main concern related to safety is liability, which is the biggest obstacle to shared track in the US (Phraner et al. [2]).

4.3.4.1 Liability It is the legal concept used to measure financial value of potential damage is liability. A systematic approach to liability protection is the use of risk evaluation, which results in measurement of system design features that increase or reduce risk. In Xalapa where people walk on and live close to the track, which already represents a liability issue, proving that by implementing the concepts (e.g. RWT) the risk within the corridor is reduced, is very valuable to gain support for the system.

4.3.4.2 Risk analysis It focuses on impacts that proposed changes exert on the safety of a specific corridor. For this, past existing safety and accident data need to be obtained (Phraner et al. [2]). In Germany, risk assessment is applied to railroad and LRT shared track practices and played a key role in regulatory changes that allow shared track operation. However, railroad and transit operators need to share the risk among them. Hazard and risk analysis, operation simulation and feasibility evaluations are used as tools for shaping legal frameworks, influences public opinion and convinces freight train operators. If accident data is not available, typical cases will be used to perform the analysis (Phraner et al. [2]).

\section{Evaluation}

Shared track and trails compete for funding with other transportation projects and do so under disadvantageous conditions due to their complexity; hence it is important to prove their superior social, environmental, and economic benefits. To perform an objective and transparent proof of benefits, it is necessary to ensure an optimal and formalized procedure for project evaluation. The evaluation proposed in this study is based on a German scheme used as a legal requirement for large PuT projects (i.e. $>25$ million Euros) (ITP and VWI [16]). The evaluation has also been successfully applied to other European countries adapted to China through a pilot project in Shanghai which aims at determining the feasibility of LRT systems (Martin et al. [17]). By the same token, the scheme will be adapted to Mexico in consideration to available data, socioeconomic as well as political contexts and comparison to current evaluation methods.

The evaluation's goal is to optimize the benefits of public transport investment (Martin [14]) in order select the most beneficial project among many possible courses of action and limited financial resources. The evaluation consists of costbenefit investigations (cost benefit, cost-effectiveness, value-benefit) of qualitative and quantitative aspects, investment calculation and quantification of input data, which determine the macroeconomic and social importance of public 
investment and assesses technical and economic criteria, as well as impact on the general public, the users, the environment (ITP and VWI [16]) and urban impacts (e.g. land value). Within the evaluation a subsequent cost analysis provides three kinds of values for every party involved: the cash-flow balances, the net present value of cash-flow and changes of annual figures, which provide a clue about the financial success (Martin [14]). The evaluation represents the overall economic benefit brought by the project during service, the quality of service improvement, and debt service for the complete infrastructure (Martin [14]). The evaluation is only accepted when the general economic benefit (i.e. the ration of benefits and costs) is higher than one. To adequately determine the macroeconomic impacts, the evaluation uses the "with case" and "without case" principle in yearly time intervals and the annuity method for calculation of capital costs and benefits are determined as constant annual amounts. Costs include infrastructure, vehicles, maintenance, PuT operating cost, automobile operation costs, travel time, personnel, energy, accident and noise and emissions.

\section{Conclusion}

Track sharing with trails represent solutions that make use of resources efficiently while providing benefits to society and urban environments. This is realized through implementing high quality multimodal transportation systems in places where traditionally social and urban problems exist, but their implementation is complex. The main concern is safety and distribution of responsibilities and liability. However, there are excellent examples of cost efficient solutions available which can be adapted, especially if the railroad system is still underdeveloped or tracks have extra capacity. Important is to create an implementation framework that indicates the institutional, technical and operational aspects to be considered for a safe and cost efficient system. The framework demonstrates social benefits and risks in a transparent manner so decision makers are able to understand the concept and support it. The proposed framework also describes preconditions for implementation and the characteristics that determine a corridor's suitability. The German shared track experience, due to its success, guides the way to an efficient and safe system that caters to all stakeholders. The US examples show how focusing only on one mode of rail transport reduces track productivity especially for tracks with low traffic volumes. A more balance used of the infrastructure, especially within urban areas should be perused through track sharing which could eventually grow and service their region. Current policies in Mexico provide tools that support the implementation of these systems. It is just a matter of starting in the right direction, which is the intent of this study.

\section{References}

[1] Camacho, D., Promoting a Light rail Train-with-Rail on an Underutilized Urban Freight Rail Corridor in Xalapa, Mexico. Master Thesis, MIP, Univ. of Stuttgart, Stuttgart, Germany, 2011. 
[2] Phraner, D. et al., "Supplementing and updating TCRP Report 52: Joint Operation of Light Rail Transit or Diesel Multiple Unit Vehicles with Railroads," TRB, National Research Council, Washington, DC, 2001.

[3] Naegeli, L., Weidmann, U., \& Nash, A., Checklist for Successful Application of Tram-Train Systems in Europe. Transportation Research Record, Vol. 2275, pp. 39-48. TRB, Washington, DC, 2012.

[4] Birk, L. M. et al., "Rails-with-Trails: Lessons Learned," US DOT: Cambridge, MA, 2002.

[5] Phraner, D. et al., "Germany's Track Sharing Experience: Mixed Use of Rail Corridor," TRB, National Research Council, Washington, DC, 2002.

[6] Congreso de los Estados Unidos Mexicanos, "Ley Reglamentaria del Servicio Ferroviario," Mexico DF, 2015.

[7] Gorostiza, F. J., "Renacimiento de los ferrocarriles mexicanos de carga," Asociación Mexicana de Ferrocarriles, México, DF, 2011.

[8] IDB Inter American Development Bank. "Plan de Acción Xalapa Sostenible," IDB, Washington, DC, 2015.

[9] Van der Bijl, R. \& Kühn, A. (2009). "Tramtrain: The 2nd Generation - New Criteria for the 'Ideal' Tramtrain City". Lightrail (Online). Available: http://www.lightrail.nl/TramTrain. (Accessed: April, 2015).

[10] Creighton, J. L., The public participation handbook: making better decisions through citizen involvement. Jossey-Bass: San Francisco, 2005.

[11] ScanRail Consult, "CrossRail - Integrating local and regional rail, incl. cross border aspects," European Community, Competitive and Sustainable Growth Programme, Denmark, 2001.

[12] Chu, Z., Modellierung der Wartezeitfunktion bei Leistungsuntersuchungen im Schienenverkehr unter Berücksichtigung der transienten Phase, Neues verkehrswissenschaftliches Journal, Ausgabe 10, Books on Demand $\mathrm{GmbH}$, Norderstedt, 2014.

[13] Pachl, J. et al., Railway operation and control. VDT Rail Publishing: Mountlake Terrace, 2002.

[14] Martin, U., Performance Evaluation (Chapter 12). Railway Timetable \& Traffic. Eurailpress: Hamburg, pp. 192-208, 2008.

[15] Martin, U., "Capacity research in urban rail-bounded transportation with special consideration of mixed traffic." Railway and Transportation Engineering Institute, University of Stuttgart, Stuttgart, 2013.

[16] ITP Intraplan Consult GmbH \& VWI Verkehrswissenschaftliches Institut Stuttgart GmbH, "Standarisierte Bewertung von Verkehrswegeinvestitionen des ÖPNV und Folgenkostenrechnung," BMVBS, Berlin, 2006.

[17] Martin, U. et al., "Standardisierte Bewertung für Straßenbahnmaßnahmen in China," for the Shanghai YOUDE Energy-saving Tech. Development Co., Ltd., Verkehrswissenschaftliches Institut Stuttgart GmbH, Stuttgart, 2014. 